\title{
Jacalin Has Chemopreventive Effects on Colon Cancer Development
}

\author{
Thais Herrero Geraldino, ${ }^{1}$ Patricia Modiano, ${ }^{2}$ Luciana Chain Veronez, \\ Milena Flória-Santos, ${ }^{3}$ Sergio Britto Garcia, ${ }^{4}$ and Gabriela Pereira-da-Silva ${ }^{1,3}$ \\ ${ }^{1}$ Postgraduate Program in Basic and Applied Immunology, Ribeirão Preto School of Medicine, University of São Paulo, \\ Ribeirão Preto, SP, Brazil \\ ${ }^{2}$ Ribeirão Preto College of Nursing, University of São Paulo, Ribeirão Preto, SP, Brazil \\ ${ }^{3}$ Postgraduate Program in Public Health Nursing, Ribeirão Preto College of Nursing, University of São Paulo, Ribeirão Preto, SP, Brazil \\ ${ }^{4}$ Department of Pathology, Ribeirão Preto School of Medicine, University of São Paulo, Ribeirão Preto, SP, Brazil
}

Correspondence should be addressed to Gabriela Pereira-da-Silva; gbisson@eerp.usp.br

Received 28 March 2017; Accepted 3 May 2017; Published 6 June 2017

Academic Editor: Ferdinando Chiaradonna

Copyright (C) 2017 Thais Herrero Geraldino et al. This is an open access article distributed under the Creative Commons Attribution License, which permits unrestricted use, distribution, and reproduction in any medium, provided the original work is properly cited.

Colorectal cancer, which is one of the most common causes of cancer-related deaths worldwide, has a slow natural history that provides a great opportunity for prevention strategies. Plant-derived natural products have received considerable attention because of their inherent colorectal cancer chemopreventive effects. The plant lectin jacalin specifically recognizes the tumor-associated Thomsen-Friedenreich antigen and has antiproliferative effects on human colon cancer cells, highlighting its potential antitumor activity. To evaluate jacalin's potential application in colorectal cancer chemoprevention, we studied its effects on the early stages of carcinogenesis. Balb/c mice were given 4 intrarectal deposits of $0.1 \mathrm{ml}$ solution of Methyl- $\mathrm{N}^{\prime}$-Nitro-N-Nitroso-Guanidine $(5 \mathrm{mg} / \mathrm{ml})$ twice a week (with a 3-day interval) for 2 weeks. Starting 2 weeks before carcinogen administration, animals were treated orally with jacalin $(0.5$ and $25 \mu \mathrm{g})$ three times a week (on alternate weekdays) for 10 weeks. We show that jacalin treatment reduced the number of preneoplastic lesions in carcinogen-exposed mice. This anticarcinogenic activity was associated with decreased colonic epithelial cell proliferation and stromal COX-2 expression and with increased intestinal production of TNF- $\alpha$. Our results demonstrate that jacalin is able to modulate the early stages of colon carcinogenesis and emphasize its promising chemopreventive activity in colorectal cancer.

\section{Introduction}

Colorectal cancer (CRC) is one of the most common causes of cancer-related deaths worldwide [1]. CRC development is a slow process that has a natural history of transition from normal crypts through adenoma to overt adenocarcinoma, providing a great opportunity for prevention and intervention strategies. Although the early detection of invasive lesions and precursor adenomatous polyps reduces morbimortality, only a few cases of CRC have been diagnosed in early stages [2]. Currently, most attention has focused on screening for chemopreventive agents to reduce the number of CRC patients.

Cancer chemoprevention uses natural, synthetic, or biological substances to reverse, suppress, or prevent the initial phase of carcinogenesis or the progression of neoplastic cells to cancer [3]. Epidemiological studies have suggested that dietary nutrients from fruits and vegetables contribute to keeping balanced cell proliferation and preventing carcinogenesis. Moreover, phytonutrients have received considerable attention because of their low cost and wide safety. Experimental evidence has established the potential colorectal cancer chemopreventive effects of plant-derived natural products $[4,5]$.

Plant lectins, carbohydrate-binding proteins distributed in a variety of plant species, are gaining clinical implications because of their potential antitumor properties. These molecules can recognize the altered glycosylation of cancer cells, mostly inhibiting proliferation and inducing tumor cell death [6-8]. Jacalin, a noncytotoxic lectin extracted from jackfruit 


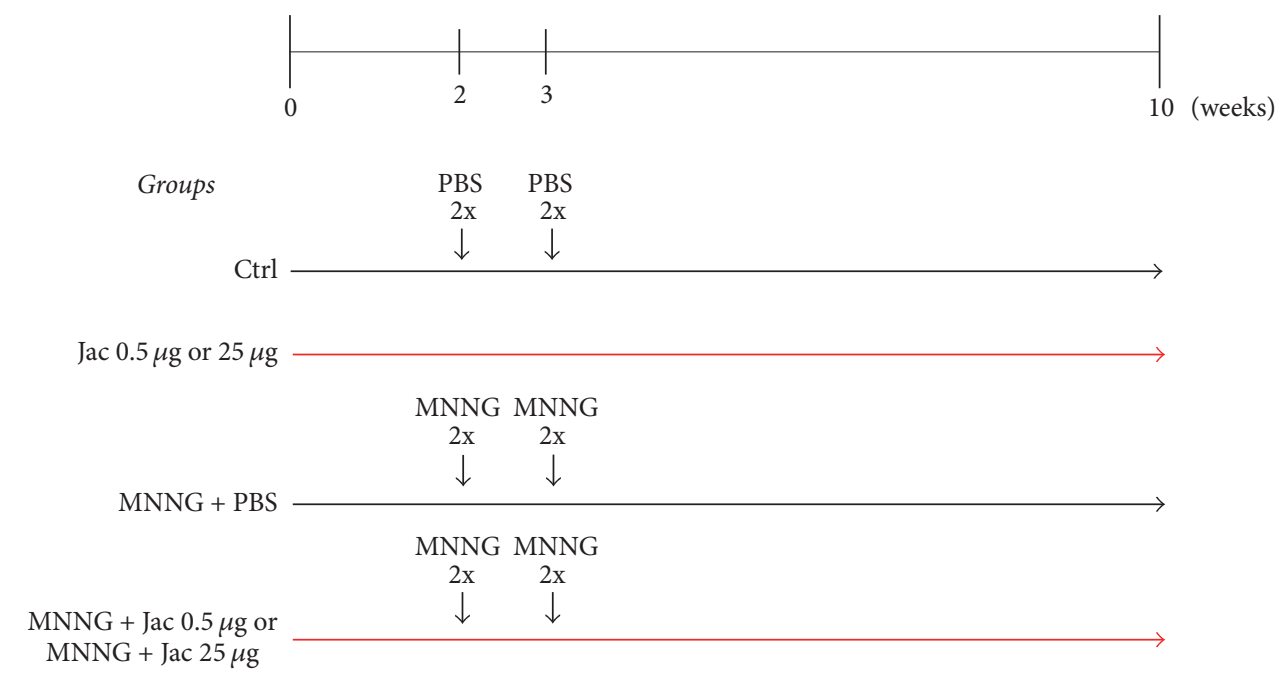

FIGURE 1: Treatment protocol. Mice received 4 successive intrarectal deposits of $0.1 \mathrm{ml}$ of PBS or MNNG solution (5 mg/ml) twice a week for 2 weeks. Starting 2 weeks before carcinogen administration, animals were treated orally $(0.1 \mathrm{ml} / \mathrm{mouse})$ with PBS $(\rightarrow)$ or jacalin $(0.5 \mathrm{and} 25 \mu \mathrm{g})$ $(\rightarrow)$ three times a week for 10 weeks. After 10 weeks of treatment, mice were euthanized, and the colons were removed, fixed, and processed for histological and immunohistochemical analysis.

(Artocarpus heterophyllus) seeds, specifically recognizes the Thomsen-Friedenreich antigen (TF-Gal $\beta 1-3$ GalNAc), which is expressed in more than $85 \%$ of human carcinomas, and has antiproliferative effects on human colon cancer cells, highlighting its potential antitumor activity [9]. Over the last few years, jacalin has emerged as a candidate carrier for delivery of cancer therapeutics [10, 11]. However, to date, its in vivo direct antitumor activity has not been investigated. To evaluate jacalin's potential application in colorectal cancer chemoprevention, we studied its effects on the early stages of carcinogenesis.

\section{Materials and Methods}

2.1. Jacalin Purification. Jacalin was isolated from the seeds of Artocarpus heterophyllus by affinity chromatography on immobilized D-galactose Sepharose column, as previously described [12]. Sample purity was evaluated by $12 \%$ SDS/PAGE under reducing conditions and was based on the presence of protein bands of 11.4 and $14.7 \mathrm{kDa}$ and the absence of $13 \mathrm{kDa}$ band corresponding to Artin-M. Protein concentration was measured by BCA protein assay kit (Pierce). Jacalin diluted in PBS was used in the assays.

2.2. Mice and Treatment Protocol. 6-Week-old Male Balb/c mice were housed at the Animal Facility of Ribeirão Preto College of Nursing, the University of São Paulo (Ribeirão Preto, SP, Brazil). Animals were maintained at $22 \pm 2^{\circ} \mathrm{C}$ with $55 \%$ humidity on a $12 \mathrm{~h}-12 \mathrm{~h}$ light/dark cycle, receiving chow and water ad libitum. The experimental protocol was performed in accordance with the guidelines of the Animal Care and Ethics Committee of the University of São Paulo. After 2 weeks of acclimation period, mice were randomly distributed into six groups (8 mice each) and were injected with PBS or Methyl-N $\mathrm{N}^{\prime}$-Nitro-N-Nitroso-Guanidine
(MNNG, Sigma-Aldrich, Louis, MO, USA) (4 successive doses of MNNG $5 \mathrm{mg} / \mathrm{ml}$; intrarectal deposits of $0.1 \mathrm{ml}$ ) twice a week (separated by a 3-day interval) for 2 weeks, as illustrated in Figure 1. Jacalin treatment started 2 weeks before carcinogen administration. Mice were treated orally $(0.1 \mathrm{ml} /$ mouse $)$ with jacalin $(0.5$ and $25 \mu \mathrm{g})$ three times a week (on alternate weekdays) for 10 weeks (Figure 1). At the end of the 10th week, mice were euthanized by $\mathrm{CO}_{2}$ exposure, and the colons were removed, longitudinally opened, fixed flat in $4 \%$ neutral paraformaldehyde buffer, and processed for histological and immunohistochemical analysis. Small pieces $(5 \mathrm{~mm})$ of the distal colon were removed for cytokine analysis.

2.3. Histological Analysis. Colon tissue samples were sectioned, stained with H\&E, and analyzed under light microscopy in a double-blind manner by two histopathologists. Dysplastic aberrant crypt foci (ACF) were identified at $200 \mathrm{x}$ magnification and counted at 400x magnification, according to previously reported criteria $[13,14]$. In brief, dysplastic lesions were assessed in transversal sections, and dysplastic patterns ranging from mild to moderate dysplasia were counted in 20 microscopic fields for each carcinogen-treated animal. The dysplasia-i (index) was expressed as the ratio between dysplastic and nondysplastic crypts. Relative values for ACF-i (index) were calculated as their total number per $\mathrm{mm}^{2}$.

2.4. Immunohistochemical Procedures. Primary antibodies were obtained from Novocastra Laboratories (Newcastle, UK). The streptavidin-biotin method (Novostain Universal Detection Kit, Novocastra Laboratories, Newcastle, UK) was used with anti-PCNA (clone PC10 at 1:100), anticaspase-3 (clone JHM62 at 1:50), and anti-COX-2 (clone $4 \mathrm{H} 12$ at $1: 100)$ monoclonal antibodies. Paraffin-embedded colon tissue sections $(4 \mu \mathrm{m})$ were processed as described 


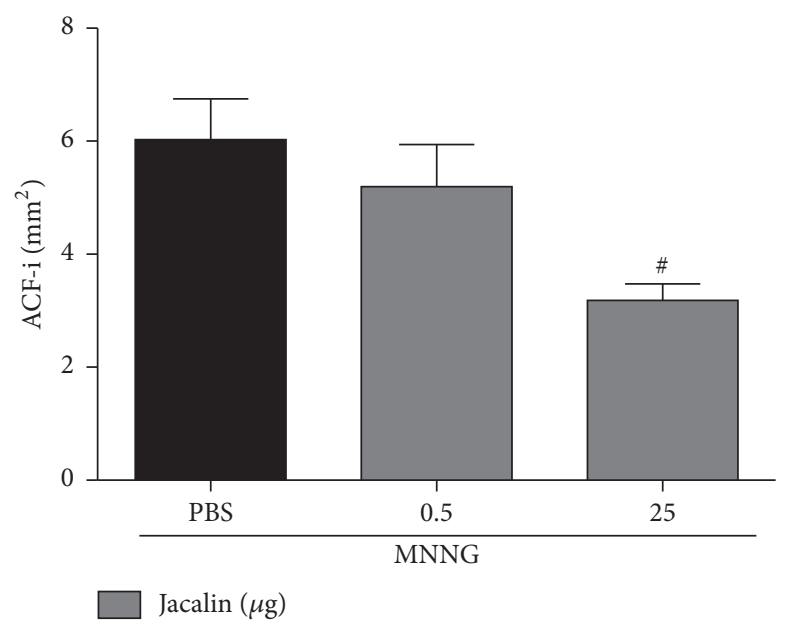

(a)

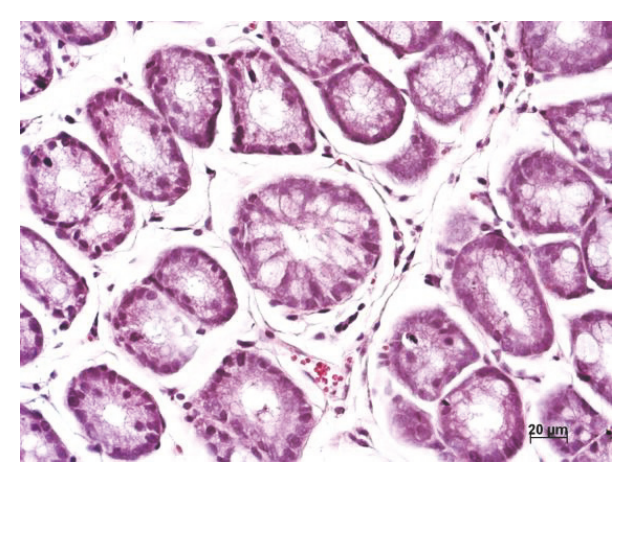

(b)

FIGURE 2: Jacalin treatment reduces the number of aberrant crypt foci in mice colon. (a) Quantification of aberrant crypt foci. The aberrant crypt foci index (ACF-i) shows the number of lesions per $\mathrm{mm}^{2}$. (b) Representative histological image of a characteristic ACF with compressed cryptal luminal opening (400x magnification, scale bars represent $20 \mu \mathrm{m}$ ). Statistical analysis: one-way analysis of variance. ${ }^{\#}$ Compared to PBS group. ${ }^{\#} P<0.05$.

previously [15] and counterstained with hematoxylin. A tonsil slide was used for control.

\subsection{PCNA, Cleaved Caspase-3, and COX-2 Analysis. To} estimate colonic cell proliferation or death and colonic inflammation, the colon tissue slices were immunostained with anti-PCNA, anti-Caspase-3, or anti-COX-2 antibodies, respectively. At least 20 perpendicular well-oriented normalappearing colon crypts per animal were examined under light microscopy in a double-blind manner by two investigators. The index of colonic crypt cells expressing proliferating cell nuclear antigen (PCNA-i) was calculated from the ratio of positively stained nuclei to a total number of nuclei counted, whereas caspase- 3 and COX-2 indexes (Caspase-3-i and COX-2-i) were expressed as the number of stained cells in the intercrypt spaces.

2.6. Cytokine Quantification. For cytokine detection, colon was homogenized in $1 \mathrm{ml}$ ice-cold homogenization buffer (PBS with protease inhibitor cocktail, Roche). The supernatant was collected by centrifugation (15 minutes, $5.000 \mathrm{rpm}, 4^{\circ} \mathrm{C}$ ) and stored at $-20^{\circ} \mathrm{C}$ until use. The levels of IL-1 $\beta$, IL-6, IL-10, IL-12p70, TNF- $\alpha$, IFN- $\gamma$, and TGF$\beta$ were measured by ELISA (BD OptEIA ${ }^{\mathrm{TM}}$ ), according to the manufacturer's protocol. Cytokine concentration was determined with reference to a standard curve of murine recombinant cytokines and normalized to the weight of the colons.

2.7. Statistical Analysis. Data were analyzed using the statistical program GraphPad Prism 5.0. For all experiments, one-way ANOVA (Kruskal-Wallis) and Dunn's multiple comparison post hoc tests were applied for samples with nonnormal distribution, and one-way analysis of variance was used for those with normal distribution. A probability of
$P<0.05$ was considered significant. Results were expressed as mean \pm SEM.

\section{Results}

3.1. Aberrant Crypt Foci Quantification. To evaluate whether jacalin has a chemopreventive activity in carcinogen-exposed mice, colonic preneoplastic lesions-aberrant crypt foci (ACF)-were counted 10 weeks after the first injection of MNNG. We observed that all MNNG-exposed animals developed ACF in the colon (Figure 2(a)). However, the number of ACF was significantly lower in the group treated with the higher dose of jacalin $(25 \mu \mathrm{g})$ when compared to the untreated group. No difference was observed between untreated group and that treated with the lower dose of jacalin $(0.5 \mu \mathrm{g})$. These results demonstrate a potential chemopreventive activity of jacalin against colon cancer development.

3.2. Jacalin Effects on Cell Proliferation and Apoptosis. Given that increased cell proliferation and apoptosis have been associated with development of colon tumors [16], we next evaluated whether jacalin interferes with colonic epithelial cell proliferation and apoptosis rates in the "normal-appearing" crypts of carcinogen-exposed mice. The MNNG-exposed group showed a significant increase of colonic mucosal cell proliferation as demonstrated by PCNA immunoreactivity (PCNA-positive epithelial cells, Figure 3(a)). Treatment with jacalin reduced PCNA index; the group treated with the higher dose showed lower PCNA index compared to that treated with the lower dose. On the other hand, the apoptosis indexes (cleaved caspase-3-positive epithelial cells) were similar in all groups (Figure 3(b)). These results show that jacalin has antiproliferative activities on colonic epithelial cells. 


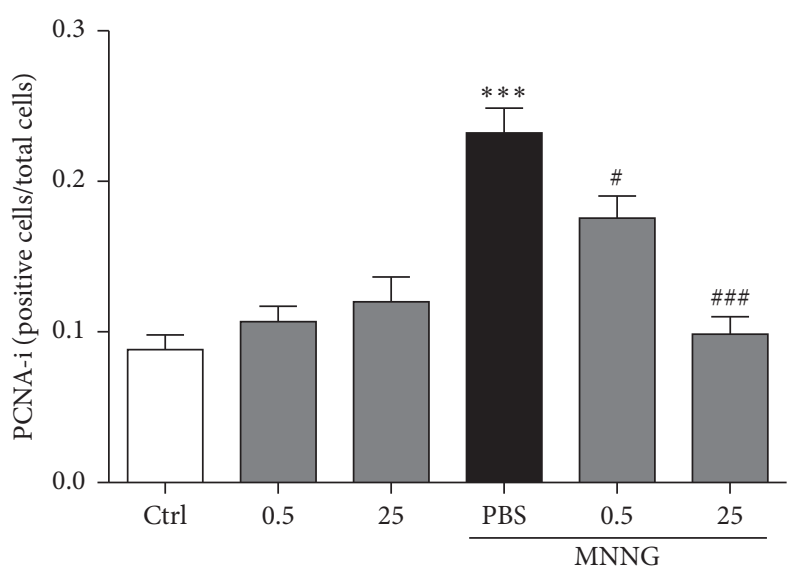

Jacalin $(\mu \mathrm{g})$

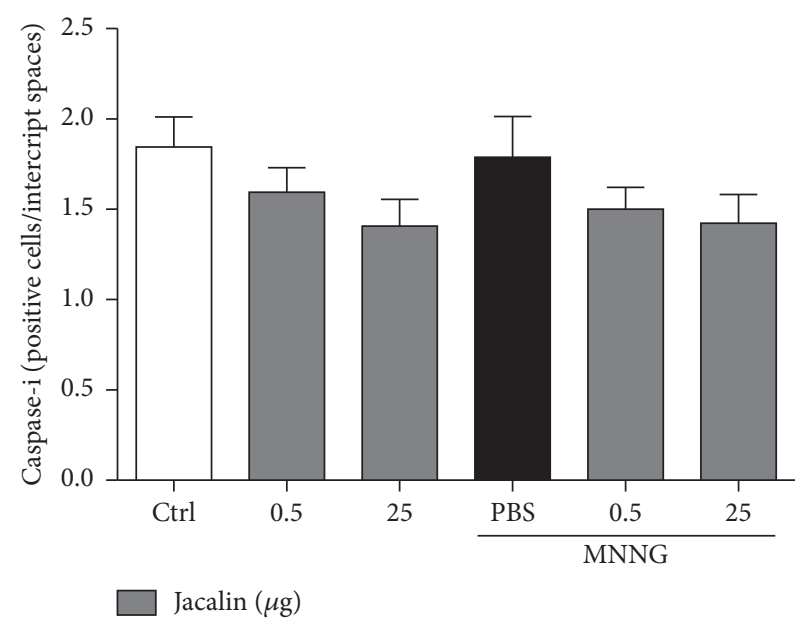

(b)

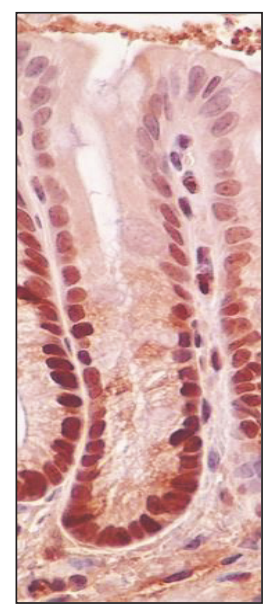

(e)

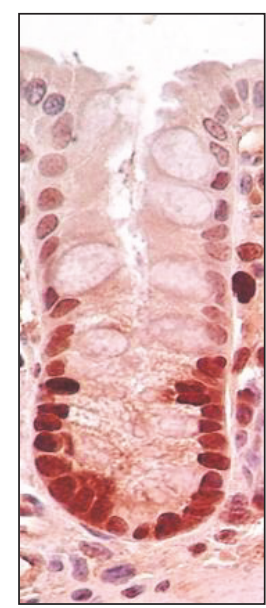

(f)

FIGURE 3: Jacalin treatment affects colonic epithelial cell proliferation but not apoptosis. (a) Proliferative activity in the colon was assessed by using proliferating cell nuclear antigen (PCNA) antibody. The index of colonic crypt cells expressing proliferating cell nuclear antigen (PCNA-i) was calculated from the ratio of positively stained nuclei to a total number of nuclei counted. (b) Apoptotic cells were detected by caspase-3 immunoreactivity in colonic stromal cells. Apoptosis index shows the number of stained cells in the intercrypt spaces. (c) Representative immunohistochemistry images of proliferating cells of the control group; (d) MNNG-exposed group; (e) MNNG-exposed group treated with jacalin $0.5 \mu \mathrm{g}$; and (f) MNNG-exposed group treated with jacalin $25 \mu \mathrm{g}$. Results are expressed as mean \pm SEM for each group. Statistical analysis: (a) one-way analysis of variance and (b) one-way ANOVA (Kruskal-Wallis) and Dunn's multiple comparison post hoc tests. ${ }^{*}$ Compared to control group. ${ }^{\#}$ Compared to PBS group. ${ }^{\#} P<0.05 ;{ }^{* * *}$ or ${ }^{\# \# \#} P<0.001$.

3.3. COX-2 Expression and Cytokine Production. Cyclooxygenase-2 and proinflammatory cytokines are important cofactors in the pathogenesis of cancer [17]. These observations prompted us to investigate COX-2 expression and cytokine production in the colonic tissue of jacalin-treated mice. Administration of the higher dose of jacalin decreased the number of COX-2 positive cells in both MNNG-exposed and control (MNNG-unexposed) groups (Figure 4).

To study the effects of jacalin on the production of antiand proinflammatory cytokines, TNF- $\alpha$, IFN- $\gamma$, IL- $1 \beta$, IL12 p70, IL- 6 , TGF- $\beta$, and IL-10 contents in colon homogenates from carcinogen-exposed mice were determined by ELISA. Compared to the control group, MNNG administration did not alter the cytokine profile. In contrast, jacalin administration $(25 \mu \mathrm{g})$ to both MNNG-exposed and unexposed mice led to increased levels of the pro- and anti-inflammatory cytokines TNF- $\alpha$ and TGF- $\beta$, respectively (Figure 5). No differences in the production of IFN- $\gamma$, IL-1 $\beta$, IL-12p70, IL-6, and IL-10 were observed among the groups. These results indicate that jacalin modulates COX-2 expression, $\mathrm{TNF}-\alpha$, and TGF- $\beta$ production in colonic tissue during carcinogenesis.

\section{Discussion}

In the present study, using a mouse model of colon carcinogenesis induced by Methyl- ${ }^{\prime}$-Nitro-N-Nitroso-Guanidine 


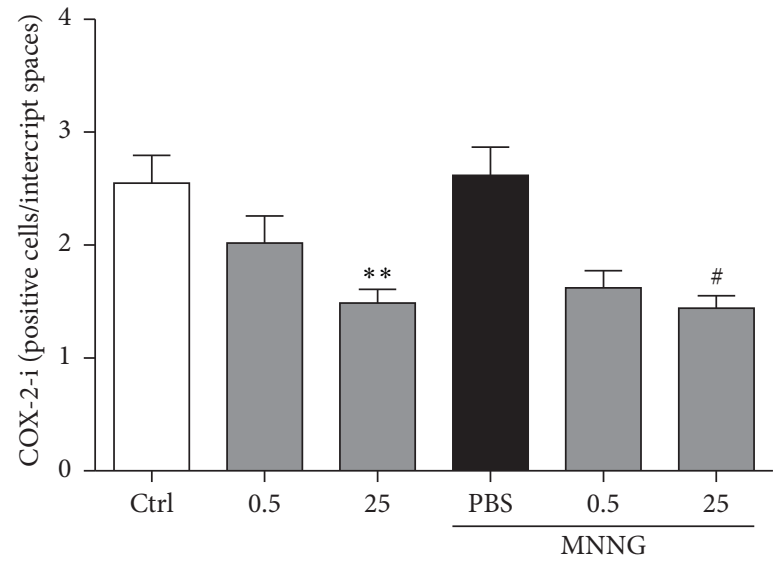

Jacalin $(\mu \mathrm{g})$

(a)

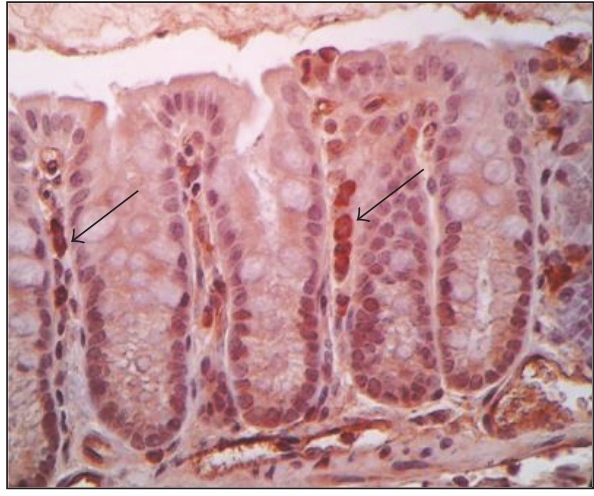

(b)

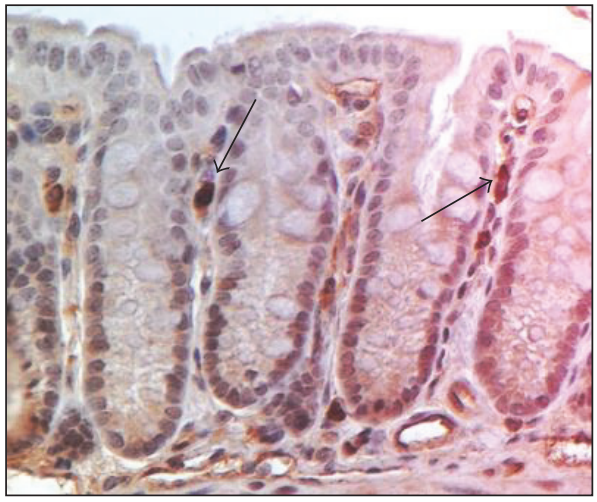

(d)

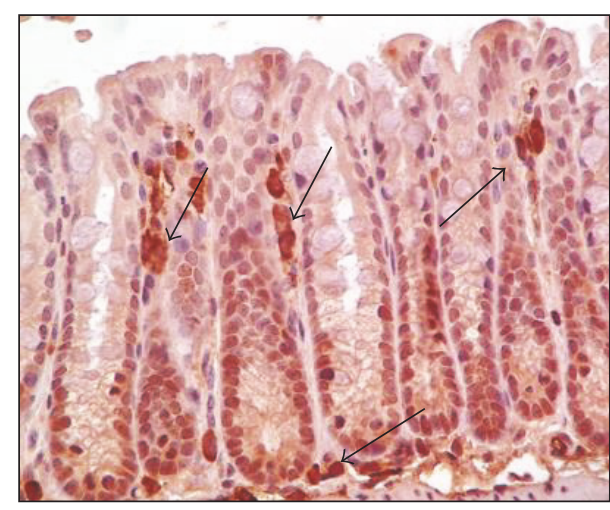

(c)

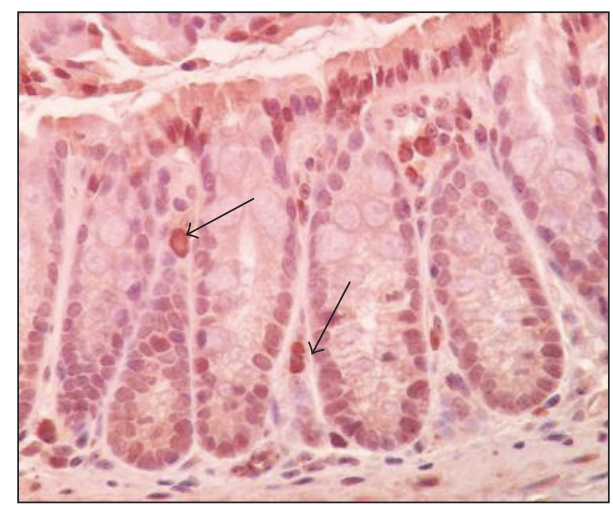

(e)

Figure 4: Downregulation of COX-2 expression in colonic tissue of jacalin-treated mice. (a) Cyclooxygenase-2 expression was evaluated using anti-COX-2 antibody. Morphometric analysis showed decreased COX-2 expression in both MNNG-exposed and unexposed animals treated with the higher dose of jacalin. (b) Representative immunohistochemistry images of COX-2 positive cells in the intercrypt spaces of the control group; (c) MNNG-exposed group; (d) MNNG-unexposed group treated with jacalin $25 \mu \mathrm{g}$; and (e) MNNG-exposed group treated with jacalin $25 \mu \mathrm{g}$. COX-2 index was calculated as the number of stained cells in the intercrypt spaces and is expressed as mean \pm SEM for each group. Statistical analysis: one-way ANOVA (Kruskal-Wallis) and Dunn's multiple comparison post hoc tests. ${ }^{*}$ Compared to control group. ${ }^{\#}$ Compared to PBS group. ${ }^{\#} P<0.05 ;{ }^{* *} P<0.01$. Arrows show COX-2-positive cells. 


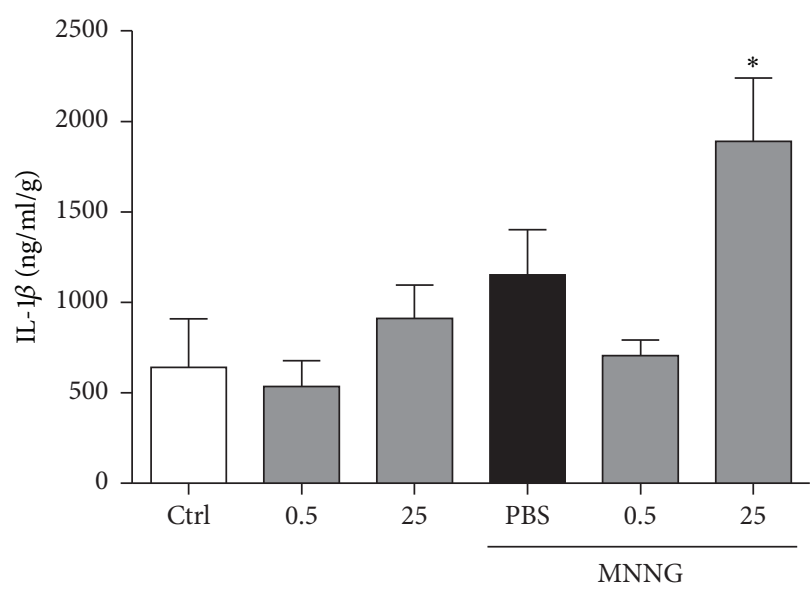

Jacalin $(\mu \mathrm{g})$

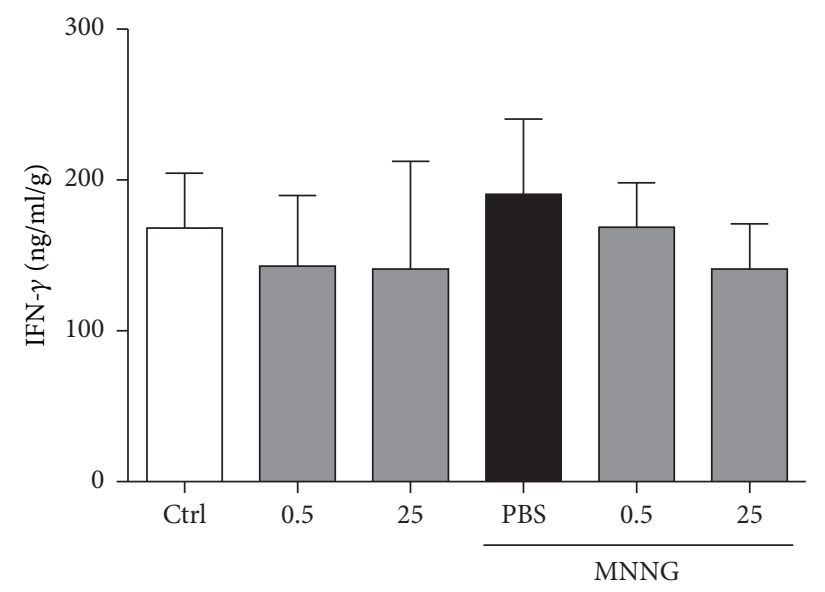

Jacalin $(\mu \mathrm{g})$

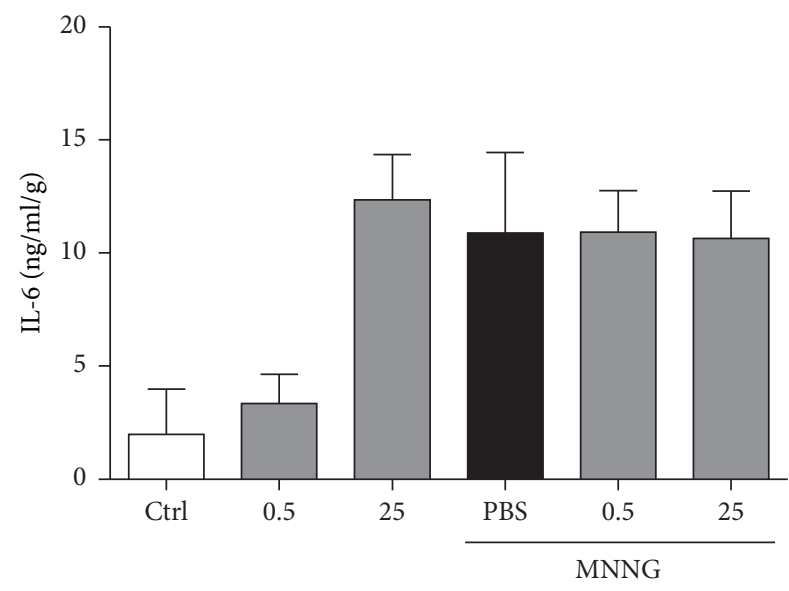

Jacalin $(\mu \mathrm{g})$

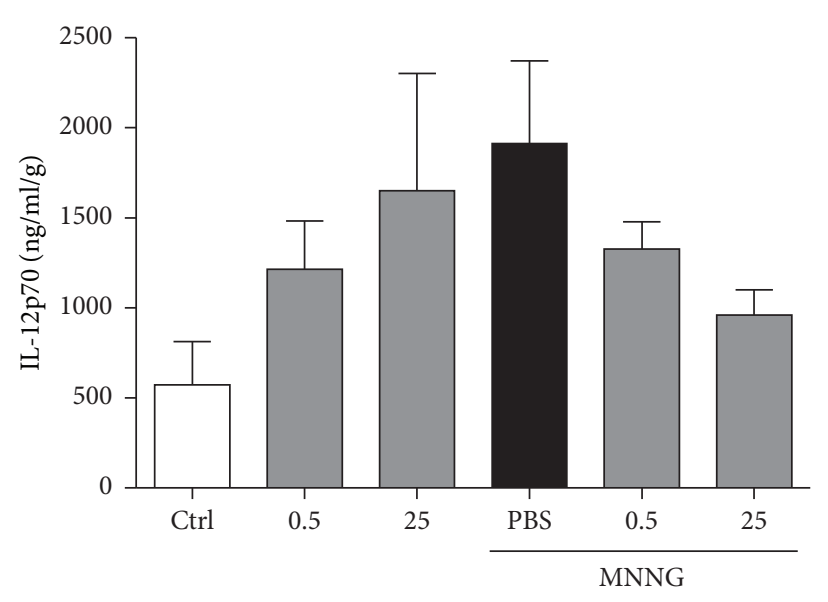

Jacalin $(\mu \mathrm{g})$

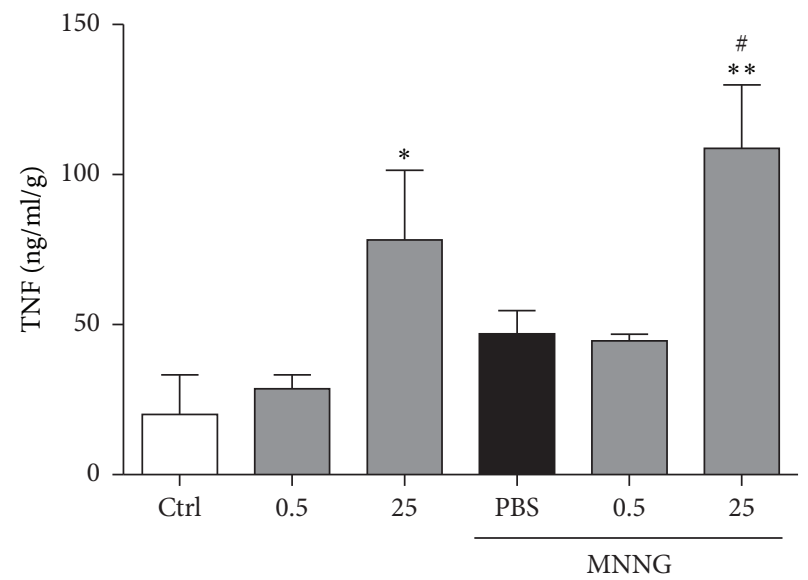

$\square$ Jacalin $(\mu \mathrm{g})$

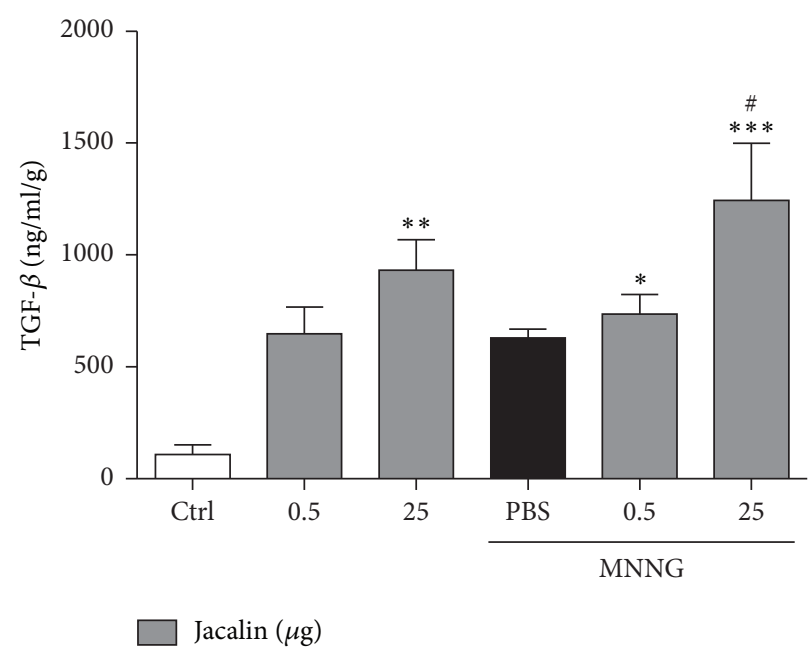

Figure 5: Continued. 


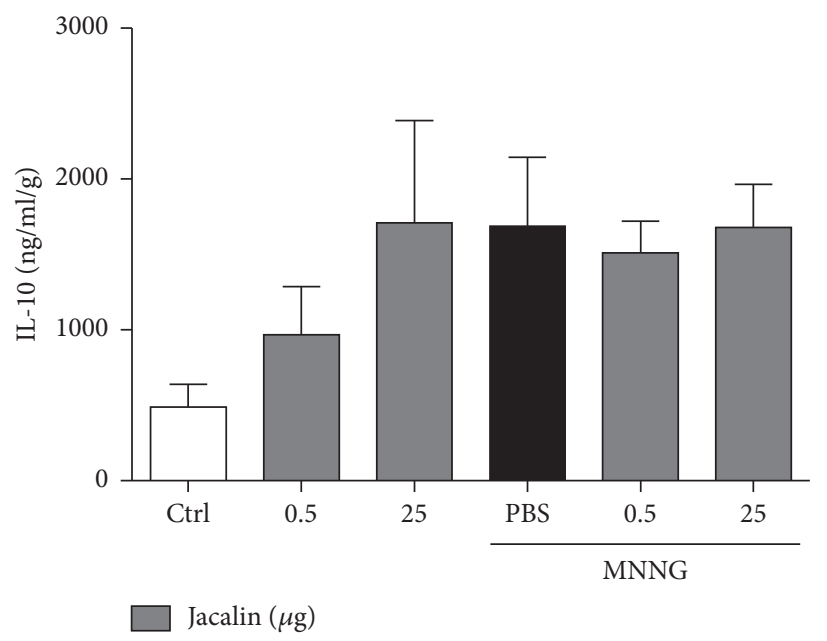

FIGURE 5: Jacalin treatment affects intestinal cytokine production. MNNG-exposed mice were treated with jacalin $(0.5$ and $25 \mu \mathrm{g})$ and proinflammatory and anti-inflammatory cytokine levels in colon homogenates were determined by ELISA. Jacalin treatment led to a significant increase in TNF and TGF- $\beta 1$ levels in colonic tissue. Results are expressed as mean \pm SEM for each group. Statistical analysis: one-way analysis of variance. ${ }^{*}$ Compared to control group; ${ }^{\#}$ compared to PBS group. ${ }^{*}$ or ${ }^{\#} P<0.05 ;{ }^{* *} P<0.01$ and ${ }^{* * *} P<0.001$.

(MNNG), we evaluated the effects of jacalin on the early stages of colonic tumorigenesis. Our results demonstrated that the lectin has chemopreventive activity, as shown by the reduced number of preneoplastic lesions (ACF) in carcinogen-exposed mice upon lectin treatment. To our knowledge, this is the first study to show that jacalin interferes with development of preneoplastic lesions in vivo.

Alterations in cell proliferation and apoptosis balance may lead to an increased risk of developing cancer [18]. Previous studies have already demonstrated that jacalin has an antiproliferative activity on human carcinoma cell line [9]. In agreement with these findings, we show that jacalin administration to carcinogen-exposed mice decreased colonic epithelial cell proliferation. These observations emphasize that lectins that specifically bind to the TF antigen, which is highly expressed in malignant and premalignant epithelia $[19,20]$, can affect intestinal epithelial cell proliferation [21] and thus have important functional effects in the colonic epithelium.

Cyclooxygenases (COX) are important regulatory enzymes in tumorigenesis. Overexpression of COX-2 and its products have been associated with various premalignant and malignant lesions of the gastrointestinal tract [22-24], and COX-2 has been posited as a potential biomarker for cancer risk and poor prognosis [24-27]. Indeed, patients bearing tumors with high levels of COX-2 have shown significantly reduced survival $[28,29]$, while a $40-50 \%$ reduction of colon cancer risk has been reported in patients using nonsteroidal anti-inflammatory drugs (NSAIDs), which are known to inhibit COX-2 [30, 31]. In addition, several studies have shown that different COX-2 inhibitors regulate the proliferation of many tumor cell types [32-35]. In CRC, the COX2 specific inhibitor NS-398 reduced the proliferation of a highly invasive mouse CRC cell line (MC-26) in association with a decrease in PCNA levels [36]. Activation of stromal COX-2 signaling has also been shown to induce proliferation of human colonic epithelial cancer cells [37]. Similarly, our results demonstrate that jacalin was able to decrease the number of COX-2 positive colonic stromal cells and reduce intestinal epithelial cell proliferation in MNNG-exposed animals, suggesting that jacalin's antiproliferative effect is related to COX-2 inhibition.

COX-2 expression is usually transient and can be rapidly induced by cytokines, lipopolysaccharide (LPS), phorbol myristate acetate (PMA), or growth factors [38]. Some inflammatory factors, such as IL- $1 \beta$ and TNF- $\alpha$, may stimulate a sustained COX-2 expression and $\mathrm{PGE}_{2}$ production in colonic tissues, promoting proliferation and invasiveness of colon cancer epithelial cells [39, 40]. Surprisingly, although jacalin treatment reduced COX-2 expression, high levels of TNF- $\alpha$ were detected in colon homogenates from carcinogen-exposed mice treated with the higher dose of the lectin. Given that TNF- $\alpha$ is known to induce colon cancer cell death both in vivo and in vitro [41, 42], we hypothesize that this cytokine, by inducing death of transformed cells, might be related with jacalin's chemopreventive effect. Indeed, we previously observed significant cell death rates among human colon adenocarcinoma cells (HT-29 cell line) exposed to supernatants from jacalin-stimulated macrophages, which contained high TNF- $\alpha$ levels [43].

Depending on the treatment conditions and cell types, TNF- $\alpha$ can induce both apoptotic and necrotic cell death [44]. Contrary to the well-known mechanisms involved in TNF- $\alpha$-induced apoptosis, the signaling pathway to necrotic cell death in response to this cytokine remains elusive. Studies have shown that reactive oxygen species (ROS) may play an important role in TNF-induced necrosis [45-48]. HT-29 cells treated with NSAIDs exhibited high levels of ROS that were able to sensitize these cells to TNF-induced cell death $[41,49]$. Given that the apoptosis index was not affected by jacalin treatment, we hypothesize that lectin, similar to NSAIDs, sensitizes transformed cells to TNF- $\alpha$-induced necrosis by 
increasing ROS production. However, further studies are needed to unravel the precise role of TNF- $\alpha$ in jacalin's anticarcinogenic activity.

In conclusion, our results demonstrate that jacalin is able to modulate the early stages of colon carcinogenesis, inhibiting development of preneoplastic lesions. Jacalin's anticarcinogenic activity was associated with decreased colonic epithelial cell proliferation and COX-2 expression and with increased intestinal production of TNF- $\alpha$. Our findings highlight the potential chemopreventive activity of jacalin in colorectal cancer.

\section{Abbreviations}

ACF: Aberrant crypt foci

COX-2: Cyclooxygenase 2

CRC: Colorectal cancer

H\&E: Hematoxylin and eosin

MNNG: Methyl-N'-Nitro-N-Nitroso-Guanidine

PCNA: Proliferating cell nuclear antigen

TF: Thomsen-Friedenreich antigen.

\section{Conflicts of Interest}

The authors declare that they have no conflicts of interest.

\section{Authors' Contributions}

Thais Herrero Geraldino, Patricia Modiano, Luciana Chain Veronez, and Gabriela Pereira-da-Silva were in charge of the experimental protocol and analysis and interpretation of the results. They participated in the preparation of the manuscript. Sergio Britto Garcia was the group pathologist. $\mathrm{He}$ participated in the analysis and interpretation of the results. Thais Herrero Geraldino and Patricia Modiano contributed equally to this work.

\section{Acknowledgments}

This study was supported by FAPESP (09/12046-0). Thais Herrero Geraldino was recipient of fellowship from CNPq, Patricia Modiano was recipient of fellowship from FAPESP (09/11002-9), and Luciana Chain Veronez is recipient of fellowship from CAPES.

\section{References}

[1] R. L. Siegel, K. D. Miller, and A. Jemal, "Cancer statistics, 2017," CA: A Cancer Journal for Clinicians, vol. 67, no. 1, pp. 7-30, 2017.

[2] T. Tanaka, "Colorectal carcinogenesis: review of human and experimental animal studies," Journal of Carcinogenesis, vol. 8, article 5, 2009.

[3] L. Zhang, X. Ren, E. Alt et al., "Chemoprevention of colorectal cancer by targeting APC-deficient cells for apoptosis," Nature, vol. 464, no. 7291, pp. 1058-1061, 2010.

[4] Y. Shukla and J. George, "Combinatorial strategies employing nutraceuticals for cancer development," Annals of the New York Academy of Sciences, vol. 1229, no. 1, pp. 162-175, 2011.
[5] E. Talero, J. Ávila-Roman, and V. Motilva, "Chemoprevention with phytonutrients and microalgae products in chronic inflammation and colon cancer," Current Pharmaceutical Design, vol. 18, no. 26, pp. 3939-3965, 2012.

[6] B. Liu, H.-J. Bian, and J.-K. Bao, "Plant lectins: potential antineoplastic drugs from bench to clinic," Cancer Letters, vol. 287, no. 1, pp. 1-12, 2010.

[7] L.-L. Fu, C.-C. Zhou, S. Yao, J.-Y. Yu, B. Liu, and J.-K. Bao, "Plant lectins: targeting programmed cell death pathways as antitumor agents," International Journal of Biochemistry and Cell Biology, vol. 43, no. 10, pp. 1442-1449, 2011.

[8] A. Almogren, J. Abdullah, K. Ghapure, K. Ferguson, V. V. Glinsky, and K. Rittenhouse-Olson, "Anti-Thomsen-Friedenreich$\mathrm{Ag}$ (anti-TF-Ag) potential for cancer therapy," Frontiers in Bioscience, vol. 4, pp. 840-863, 2012.

[9] L.-G. Yu, J. D. Milton, D. G. Fernig, and J. M. Rhodes, "Opposite effects on human colon cancer cell proliferation of two dietary Thomse-Friedenreich antigen-binding lectins," Journal of Cellular Physiology, vol. 186, no. 2, pp. 282-287, 2001.

[10] G. Obaid, I. Chambrier, M. J. Cook, and D. A. Russell, "Targeting the oncofetal thomsen-friedenreich disaccharide using jacalin-PEG phthalocyanine gold nanoparticles for photodynamic cancer therapy," Angewandte Chemie-International Edition, vol. 51, no. 25, pp. 6158-6162, 2012.

[11] G. Obaid, I. Chambrier, M. J. Cook, and D. A. Russell, "Cancer targeting with biomolecules: a comparative study of photodynamic therapy efficacy using antibody or lectin conjugated phthalocyanine-PEG gold nanoparticles," Photochemical and Photobiological Sciences, vol. 14, no. 4, pp. 737-747, 2015.

[12] I. K. Ferreira de Miranda-Santos, M. Delgado, P. V. Bonini, M. M. Bunn-Moreno, and A. Campos-Neto, "A crude extract of Artocarpus integrifolia contains two lectins with distinct biological activities," Immunology Letters, vol. 31, no. 1, pp. 6571, 1992.

[13] V. Kannen, H. Hintzsche, D. L. Zanette et al., "Antiproliferative effects of fluoxetine on colon cancer cells and in a colonic carcinogen mouse model," PLoS ONE, vol. 7, no. 11, Article ID e50043, 2012.

[14] J. E. Paulsen, E. Namork, I.-L. Seffensen, T. J. Eide, and J. Alexander, "Identification and quantification of aberrant crypt foci in the colon of min mice - A murine model of familial adenomatous polyposis," Scandinavian Journal of Gastroenterology, vol. 35, no. 5, pp. 534-539, 2000.

[15] J. F. R. Cardoso, C. Cohen, A. A. Jordão Jr., H. Vannucchi, S. B. Garcia, and S. Zucoloto, "Light and moderate doses of ethanol in chemical carcinogenesis of the colon in rats," Nutrition and Cancer, vol. 63, no. 7, pp. 1029-1035, 2011.

[16] G. Mełeń-Mucha and H. Niewiadomska, "Frequency of proliferation, apoptosis, and their ratio during rat colon carcinogenesis and their characteristic pattern in the dimethylhydrazineinduced colon adenoma and carcinoma," Cancer Investigation, vol. 20, no. 5-6, pp. 700-712, 2002.

[17] Y. Ben-Neriah and M. Karin, "Inflammation meets cancer, with NF- $\kappa \mathrm{B}$ as the matchmaker," Nature Immunology, vol. 12 , no. 8, pp. 715-723, 2011.

[18] D. Hanahan and R. A. Weinberg, "Hallmarks of cancer: the next generation," Cell, vol. 144, no. 5, pp. 646-674, 2011.

[19] B. J. Campbell, I. A. Finnie, E. F. Hounsell, and J. M. Rhodes, "Direct demonstration of increased expression of ThomsenFriedenreich (TF) antigen in colonic adenocarcinoma and 
ulcerative colitis mucin and its concealment in normal mucin," Journal of Clinical Investigation, vol. 95, no. 2, pp. 571-576, 1995.

[20] A. M. Shamsuddin, G. T. Tyner, and G. Y. Yang, "Common expression of the tumor marker D-Galactose- $\beta$ - $[1 \rightarrow 3]$ $\mathrm{N}$-Acetyl-D-Galactosamine by different adenocarcinomas: evidence of field effect phenomenon," Cancer Research, vol. 55, no. 1, pp. 149-152, 1995.

[21] L.-G. Yu, L. C. Packman, M. Weldon, J. Hamlett, and J. M. Rhodes, "Protein phosphatase $2 \mathrm{~A}$, a negative regulator of the ERK signaling pathway, is activated by tyrosine phosphorylation of putative HLA class II-associated protein I (PHAPI)/pp32 in response to the antiproliferative lectin, jacalin," Journal of Biological Chemistry, vol. 279, no. 40, pp. 41377-41383, 2004.

[22] C. E. Eberhart, R. J. Coffey, A. Radhika, F. M. Giardiello, S. Ferrenbach, and R. N. Dubois, "Up-regulation of cyclooxygenase 2 gene expression in human colorectal adenomas and adenocarcinomas," Gastroenterology, vol. 107, no. 4, pp. 11831188, 1994.

[23] S. L. Kargman, G. P. O’Neill, P. J. Vickers, J. F. Evans, J. A. Mancini, and S. Jothy, "Expression of prostaglandin $\mathrm{G} / \mathrm{H}$ Synthase-1 and -2 protein in human colon cancer," Cancer Research, vol. 55, no. 12, pp. 2556-2559, 1995.

[24] A. J. Jordan, K. P. Becker, M. Sertemir et al., "Multiple aseptic splenic abscesses in a 15 year old patient," BMC Gastroenterology, vol. 14, no. 20, pp. 1-4, 2014.

[25] Q.-B. Wu and G.-P. Sun, "Expression of COX-2 and HER-2 in colorectal cancer and their correlation," World Journal of Gastroenterology, vol. 21, no. 20, pp. 6206-6214, 2015.

[26] L. Peng, Y. Zhou, Y. Wang, H. Mou, and Q. Zhao, "Prognostic significance of COX-2 Immunohistochemical expression in colorectal cancer: a meta-analysis of the literature," PLOS ONE, vol. 8, no. 3, Article ID e58891, 2013.

[27] L. T. Soumaoro, H. Uetake, T. Higuchi, Y. Takagi, M. Enomoto, and K. Sugihara, "Cyclooxygenase-2 expression: a significant prognostic indicator for patients with colorectal cancer," Clinical Cancer Research, vol. 10, no. 24, pp. 8465-8471, 2004.

[28] C. J. Buskens, B. P. Van Rees, A. Sivula et al., "Prognostic significance of elevated cyclooxygenase 2 expression in patients with adenocarcinoma of the esophagus," Gastroenterology, vol. 122, no. 7, pp. 1800-1807, 2002.

[29] T. Fujimura, T. Ohta, K. Oyama, T. Miyashita, and K. Miwa, "Role of cyclooxygenase-2 in the carcinogenesis of gastrointestinal tract cancers: a review and report of personal experience," World Journal of Gastroenterology, vol. 12, no. 9, pp. 1336-1345, 2006.

[30] T. M. Brasky, J. Liu, E. White et al., "Non-steroidal antiinflammatory drugs and cancer risk in women: results from the Women's Health Initiative," International Journal of Cancer, vol. 135, no. 8, pp. 1869-1883, 2014.

[31] L. A. García Rodríguez and C. Huerta-Alvarez, "Reduced risk of colorectal cancer among long-term users of aspirin and nonaspirin nonsteroidal antiinflammatory drugs," Epidemiology, vol. 12, no. 1, pp. 88-93, 2001.

[32] Y. Cao and S. M. Prescott, "Many actions of cyclooxygenase-2 in cellular dynamics and in cancer," Journal of Cellular Physiology, vol. 190, no. 3, pp. 279-286, 2002.

[33] M. D. Castellone, H. Teramoto, B. O. Williams, K. M. Druey, and J. S. Gutkind, "Prostaglandin E2 promotes colon cancer cell growth through a Gs-axin- $\beta$-catenin signaling axis," Science, vol. 310, no. 5753, pp. 1504-1510, 2005.
[34] B. Xin, Y. Yokoyama, T. Shigeto, and H. Mizunuma, "Anti-tumor effect of non-steroidal anti-inflammatory drugs on human ovarian cancers," Pathology and Oncology Research, vol. 13, no. 4, pp. 365-369, 2007.

[35] T. Wun, H. McKnight, and J. M. Tuscano, "Increased cyclooxygenase-2 (COX-2): A potential role in the pathogenesis of lymphoma," Leukemia Research, vol. 28, no. 2, pp. 179-190, 2004.

[36] M. Yao, E. C. Lam, C. R. Kelly, W. Zhou, and M. M. Wolfe, "Cyclooxygenase-2 selective inhibition with NS-398 suppresses proliferation and invasiveness and delays liver metastasis in colorectal cancer," British Journal of Cancer, vol. 90, no. 3, pp. 712-719, 2004.

[37] Y. Zhu, M. Zhu, and P. Lance, "Stromal COX-2 signaling activated by deoxycholic acid mediates proliferation and invasiveness of colorectal epithelial cancer cells," Biochemical and Biophysical Research Communications, vol. 425, no. 3, pp. 607612, 2012

[38] W. L. Smith, D. L. DeWitt, and R. M. Garavito, "Cyclooxygenases: structural, cellular, and molecular biology," Annual Review of Biochemistry, vol. 69, pp. 145-182, 2000.

[39] M. Zhu, Y. Zhu, and P. Lance, “TNF $\alpha$-activated stromal COX-2 signalling promotes proliferative and invasive potential of colon cancer epithelial cells," Cell Proliferation, vol. 46, no. 4, pp. 374381, 2013.

[40] Y. Zhu, M. Zhu, and P. Lance, "IL1B-mediated Stromal COX2 signaling mediates proliferation and invasiveness of colonic epithelial cancer cells," Experimental Cell Research, vol. 318, no. 19, pp. 2520-2530, 2012.

[41] C. Giardina, H. Boulares, and M. S. Inan, "NSAIDs and butyrate sensitize a human colorectal cancer cell line to TNF- $\alpha$ and Fas ligation: the role of reactive oxygen species," Biochimica et Biophysica Acta - Molecular Cell Research, vol. 1448, no. 3, pp. 425-438, 1999.

[42] A. Rizzo, V. De Mare, C. Rocchi et al., "Smad7 induces plasticity in tumor-infiltrating Th17 cells and enables TNF-alphamediated killing of colorectal cancer cells," Carcinogenesis, vol. 35, no. 7, pp. 1536-1546, 2014.

[43] C. Danella Polli, L. Pereira Ruas, L. Chain Veronez et al., "Jacalin-activated macrophages exhibit an antitumor phenotype," BioMed Research International, vol. 2016, Article ID 2925657, 2016.

[44] G. Denecker, D. Vercammen, M. Steemans et al., "Death receptor-induced apoptotic and necrotic cell death: differential role of caspases and mitochondria," Cell Death and Differentiation, vol. 8, no. 8, pp. 829-840, 2001.

[45] M. Li and A. A. Beg, "Induction of necrotic-like cell death by tumor necrosis factor alpha and caspase inhibitors: novel mechanism for killing virus-infected cells," Journal of Virology, vol. 74, no. 16, pp. 7470-7477, 2000.

[46] Y. Lin, S. Choksi, H.-M. Shen et al., "Tumor necrosis factorinduced nonapoptotic cell death requires receptor-interacting protein-mediated cellular reactive oxygen species accumulation," Journal of Biological Chemistry, vol. 279, no. 11, pp. 1082210828, 2004.

[47] D. Vercammen, R. Beyaert, G. Denecker et al., "Inhibition of caspases increases the sensitivity of L929 cells to necrosis mediated by tumor necrosis factor," The Journal of Experimental Medicine, vol. 187, no. 9, pp. 1477-1485, 1998. 
[48] D. Vercammen, G. Brouckaert, G. Denecker et al., "Dual signaling of the Fas receptor: initiation of both apoptotic and necrotic cell death pathways," Journal of Experimental Medicine, vol. 188, no. 5, pp. 919-930, 1998.

[49] C. Giardina and M. S. Inan, "Nonsteroidal anti-inflammatory drugs, short-chain fatty acids, and reactive oxygen metabolism in human colorectal cancer cells," Biochimica et Biophysica Acta-Molecular Cell Research, vol. 1401, no. 3, pp. 277-288, 1998. 


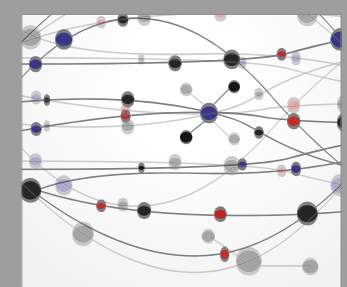

The Scientific World Journal
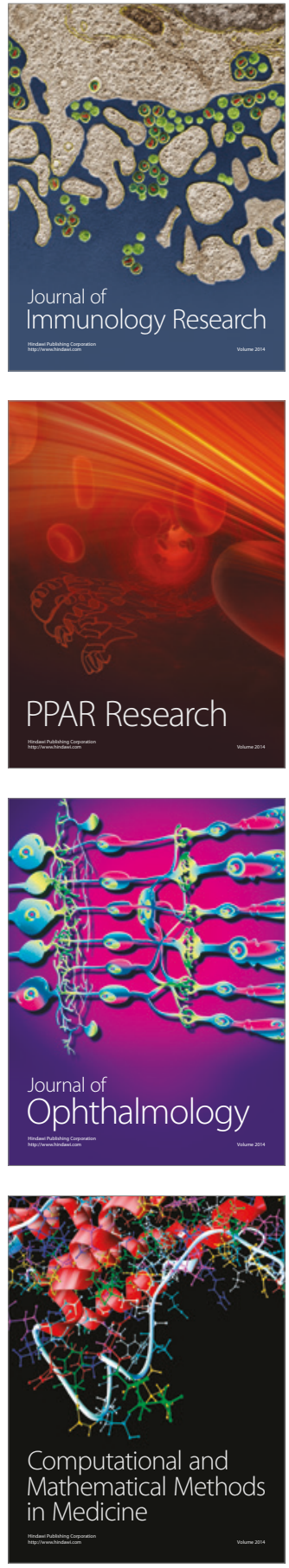

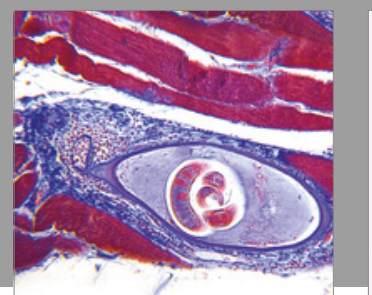

Gastroenterology Research and Practice
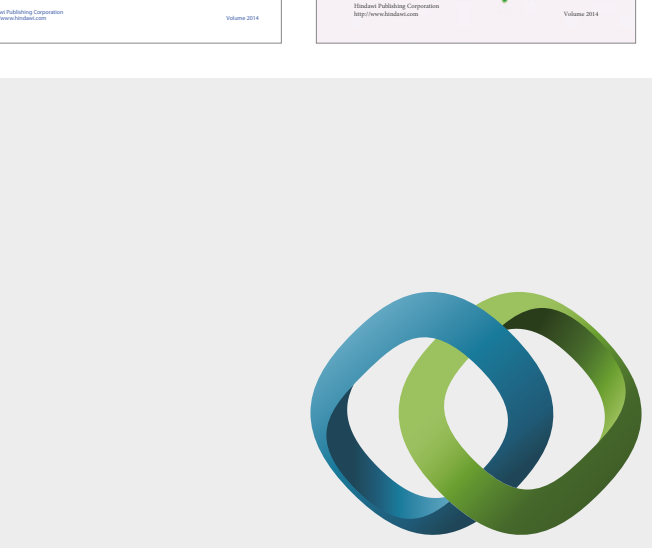

\section{Hindawi}

Submit your manuscripts at

https://www.hindawi.com
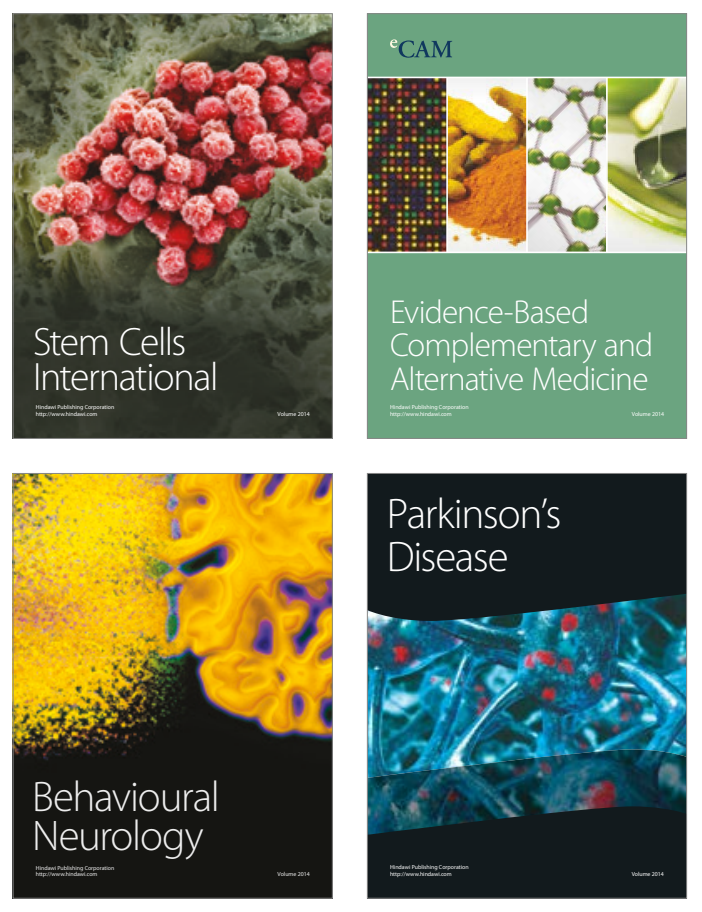
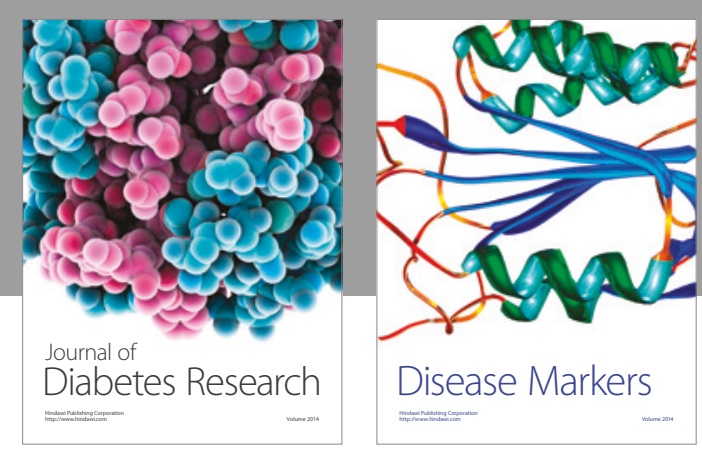

Disease Markers
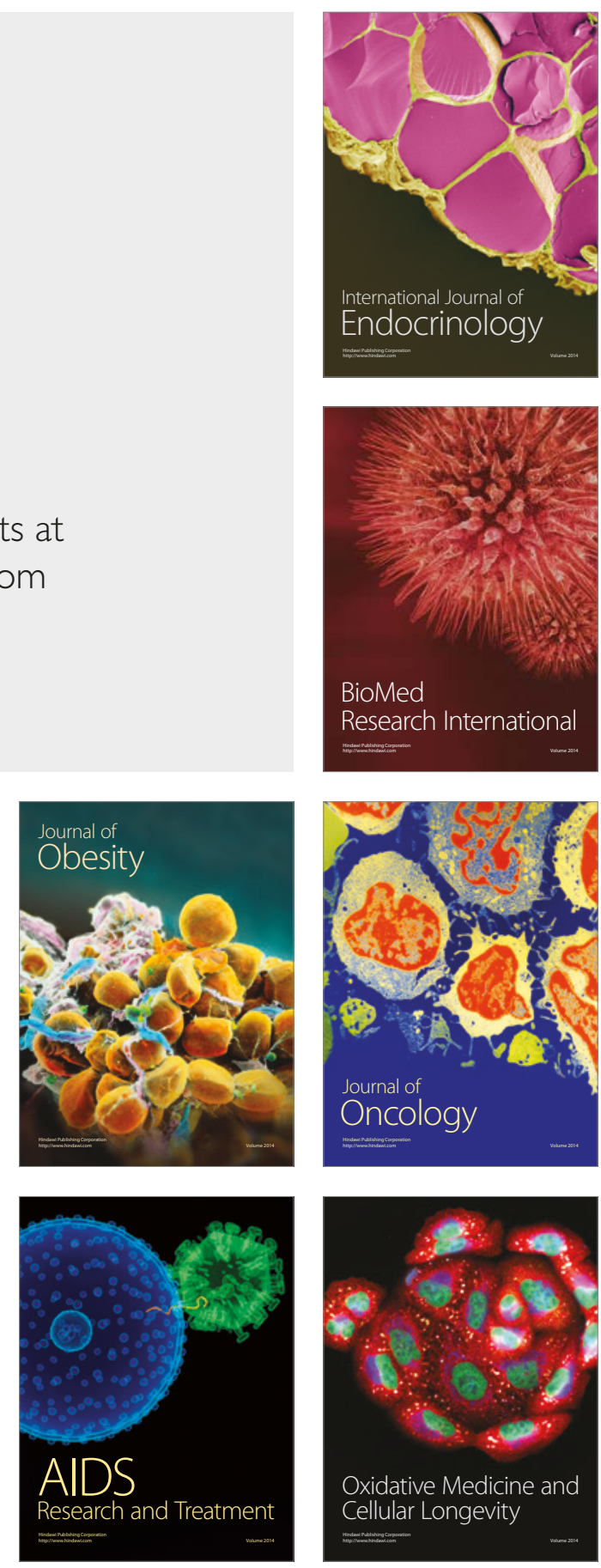